\title{
Historias de empresarias innovadoras en Colombia
}

María Carolina Ortiz, María Eugenia Morales, Edison Fredy León, Beatriz Herrera

Bogotá: Universidad Militar Nueva Granada, 2013. 220 pp.

Reseña escrita por Enit Godoy Estrella*

* Escuela Militar de Cadetes "General José María Córdova”, Bogotá, Colombia. Magíster en

Relaciones y Negocios Internacionales, docente de la Universidad Militar Nueva Granada.

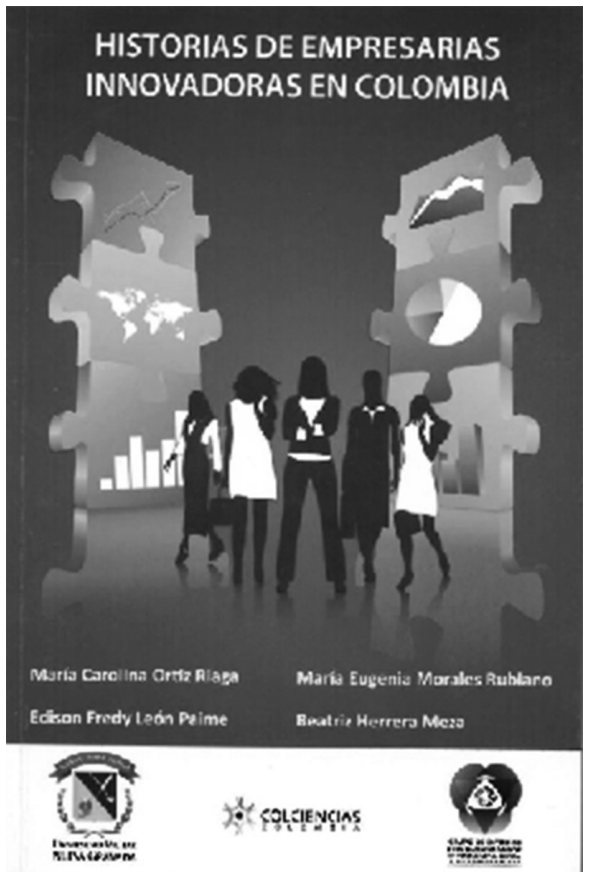

Reseña. Este es libro es el resultado de un proyecto de investigación financiado por Colciencias, que fue realizado por docentes investigadores del grupo de Estudios Contemporáneos en Contabilidad, Gestión y Organizaciones, de la Facultad de Ciencias Económicas de la Universidad Militar Nueva Granada. El proyecto se titula "Mujeres empresarias en Colombia: prácticas empresariales y procesos de innovación", y lo vienen desarrollando algunos de los autores desde 2011. En su elaboración participaron los docentes María Carolina Ortiz, psicóloga, quien lidera el proyecto; María Eugenia Morales, administradora de empresas; Beatriz Herrera, administradora de empresas, y Fredy León, contador público.

El resultado del estudio se manifiesta en dieciséis historias tomadas de una muestra poblacional de 60 empresarias, de seis ciudades principales de Colombia: Bogotá, Barranquilla, Bucaramanga, Cali, Medellín y Armenia. Aquí los autores resaltan el papel de las mujeres en la sociedad, y cómo contribuyen en la economía y la innovación; ellas, a pesar de ser esposas y madres, deben ser polifacéticas si entran en el mundo del emprendimiento.

En las primeras partes del libro se muestra la trayectoria que se va a exponer en esta etapa significativa de la investigación. El prólogo, redactado por la doctora Alexandra Montoya Restrepo, 
profesora asociada de la Universidad Nacional de Colombia, destaca el esfuerzo de los autores y justifica la necesidad de indagar por la labor empresarial e innovadora de la mujer en Colombia, ya que ella marca una diferencia, transmite sus experiencias y muestra esa perseverancia que le permite convertir sus sueños en realidad. En este prólogo se hace una revisión somera sobre la función que ha desempeñado la mujer en la historia; se realza el papel que tuvo en la mitología griega, entre los dioses en el Olimpo, y se mira cómo ha sido su rol hasta nuestros días en las diferentes esferas de la sociedad y de la vida: en la naturaleza, en la familia, en la educación, como innovadora y empresaria, en la construcción social del conocimiento, en lo laboral, en lo económico, etcétera. Todo esto la vincula con la prosperidad y la abundancia.

La introducción, por su parte, expone los conceptos clave del emprendimiento femenino desde la perspectiva de la innovación. Algunos autores anteriormente realizaron un estudio en el que identificaron los factores determinantes del emprendimiento de mujeres profesionales, como la elección de su carrera profesional, su entorno, la orientación a las actividades empresariales y la proyección al futuro en el aspecto de emprendimiento y personal (p. 11). Por tal razón, esta investigación se centra en la innovación del emprendimiento femenino, y responde a un tema estratégico gubernamental y académico que el mundo entero está trabajando e incentivando para fortalecer las organizaciones. Los autores toman el concepto de innovación según la definición que de esta se da en el Manual de Oslo: "la introducción de un nuevo, o significativamente mejorado, producto (bien o servicio), de un proceso, de un nuevo método de comercialización o de un nuevo método organizativo en las prácticas internas de la empresa, la organización del lugar de trabajo o las relaciones exteriores" (p. 13).

Ahora bien: partiendo de la innovación, la finalidad del texto consiste en mostrar las vivencias de algunas mujeres empresarias e innovadoras de Colombia. El método es básicamente narrativo, pues se basa en testimonios reales de las mujeres que constituyeron el objeto de estudio. Cada una de las experiencias que se exponen termina con una enseńanza o pensamiento sobresaliente de cada una de las emprendedoras, y con una ficha en la que se exponen los datos más importantes de las empresas y las empresarias. Grosso modo, se presentan aquí las dieciséis experiencias recopiladas en este proyecto:

1. “Tejedora de sueños en Barranquilla”. Aquí se cuenta la iniciativa empresarial de Mónica Urquijo Illera, quien se desempeña en el área textil y en el diseño de interiores. Su materia prima son las fibras vegetales "y trabaja con un grupo de 250 artesanas, mujeres cabeza de hogar ubicadas, en zonas rurales del departamento del Atlántico" (p. 17).

2. "A un paso de tus sueños". Ayleen Portilla es una empresaria bumanguesa que se dedica a la industria del calzado infantil; con su iniciativa empresarial ha dado la posibilidad de empleo a personas que no tienen preparación académica sobresaliente. Su empresa tiene impacto nacional e internacional.

3. "Innovando el sector de la belleza y los servicios de consultoría". En este capítulo se presenta la iniciativa empresarial de Doris Méndez, la cual consiste en prestar el servicio de la administración de empresas delegada y asesorar a las empresas para optimizar sus resultados. 
4. "Hadas creando motas de azúcar". Mónica Ferro es una profesional del mercadeo cuya empresa consiste en la elaboración de productos divertidos (algodón de azúcar, crispetas, obleas, etcétera). En su empresa busca darles oportunidades laborales sobre todo a las mujeres, con quienes ha formado un equipo de trabajo serio, productivo y con un ambiente laboral agradable.

5. "Innovación en la industria química". La empresa de Magaly Barrera es innovadora en buenas prácticas de gestión organizacional. Se dedica a la elaboración de productos para embellecer automóviles, con lo cual busca también el tratamiento de residuos industriales, de manera que se establezca el cuidado del medio ambiente.

6. "Nadando se llega al otro lado". Rosana Salinas es una innovadora fisioterapeuta cuya empresa, Aquasalud, se dedica a la rehabilitación acuática y al neurodesarrollo; ofrece una alternativa de rehabilitación mediante la hidroterapia, y se preocupa más por el bienestar de sus clientes, ya que les ofrece más tiempo de terapia y una atención personalizada.

7. “Abriendo tesoros nacionales para la educación". La empresa de Olga Tovar, Ecoturismo Costa Caribe, se dedica a impulsar el medio ambiente en el medio educativo, mediante la recreación con aprendizajes dirigidos a estudiantes de colegios y universidades. La empresa ofrece un parque temático en el cual se promueve la sensibilización sobre la importancia de proteger y conservar el medio ambiente.

8. "Vendiendo productos rurales por catálogo". La corporación A Mano Nativa es una empresa de la cual es propietaria y gerente Paola Muñoz. Se dedica a la venta por catálogo de artesanías de diversas comunidades colombianas. Apoya a microempresas rurales por medio de la venta de sus productos orgánicos y artesanales.

9. “Apoyando el talento humano desde la tecnología”. La empresa de la psicóloga Juliana Trujillo, E-gestión Consultoría Organizacional, perteneciente al sector de consultoría, se dedica a la evaluación y desarrollo de competencias del talento humano mediante el uso de la tecnología como herramienta de diagnóstico.

10. “Tecnología para el bienestar animal”. Sandra Cortés es una bacterióloga emprendedora que fundó Zoolab Colombia, una empresa que se dedica al diagnóstico veterinario, la cual es un área de escaso conocimiento en el país que es indispensable para establecer el diagnóstico de especies grandes y pequeñas en el ganado colombiano.

11. "El café del corazón de Colombia". Nubia Motta, emprendedora y creadora de la empresa Café Quindío, se dedica a elaborar productos innovadores que usan como base el café, entre los cuales han creado galletas, arequipes, mermeladas, entre otros. Se ofrece una alternativa diferente al café tradicional colombiano. La empresa fue ganadora del premio Grano de Oro en la Feria de Canadá.

12. "El arte plasmado en objetos decorativos de madera". Merke ltda. es una empresa del sector de las artesanías formada por la asociación entre Gilda Correa y Marta Kerguelen, quienes se dedican a la decoración mediante el diseño de piezas únicas de arte elaboradas en madera. Sus productos impactan, además, en el mercado internacional.

13. "Construyendo las bases para la innovación industrial". Mariela Gaviria es gerente y propietaria de la empresa Surtidor Industrial S.A.S. Se dedica a la producción de artí- 
culos de caucho y plástico, imprescindibles para la industria farmacéutica, aeronáutica, alimenticia y militar.

14. "De los recubrimientos dentales a las camisas para motores". Aquí se narra la experiencia de Olga Vesga, una odontóloga, quien resultó siendo gerente general de la empresa familiar, la cual se dedica a la fabricación de piezas para motores y reparación de partes en el sector industrial.

15. "Amplificando la cultura". Velouria, de la cual es propietaria Liliana Correal, es una empresa innovadora en el ámbito de la comunicación audiovisual. Su público objetivo son los jóvenes, a quienes mediante el proyecto Parlante Amarillo, apoyado por Colciencias, les ofrece un canal cultural en internet, basado en el entretenimiento y la música.

16. “Sabor Gourmet desde la Unión, Antioquia”. Las socias Gloria López y Dora Arbeláez son propietarias de Lacteos Buenavista Sabores Naurales. Esta empresa se dedica a la elaboración de lácteos tanto naturales como artesanales. La empresa ha sido ganadora varias veces del concurso Antójate de Antioquia, el cual es organizado por la Secretaría de Productividad y Competitividad de la Gobernación de Antioquia.

Luego de la relación de narraciones de vida de estas mujeres empresarias, el texto presenta sus dos últimas secciones. La primera de ellas, "Los tips de la innovación”, presenta una serie de enseńanzas, como si fueran aforismos, que se consideran importantes para tener en cuenta en el proceso de conformación e impulso de una empresa. Es posible que este capítulo sea, tal vez, innecesario, no por su contenido en sí, el cual es importante, sino porque es la repetición de las enseñanzas que hay al final de cada uno de los relatos. He aquí, quizás, una de las fallas del proceso editorial del libro.

En cuanto a la última sección, en la que vienen las conclusiones del estudio, se destacan algunas reflexiones en torno al papel que desempeńan las mujeres innovadoras en la sociedad colombiana, las cuales toman como base las narraciones recopiladas. Dentro de tales reflexiones se destacan los siguientes aspectos:

- Tanto mujeres jóvenes como mayores pueden innovar.

- Es indispensable la adquisición de capital para el emprendimiento, el cual buscan por medio de ahorros, apoyo familiar, cooperativas, bancos, apoyos institucionales o asociación con el sector privado empresarial.

- La familia es importante en la construcción e innovación de las empresas, pues estas se conforman gracias a la sociedad entre esposos, la transmisión del legado a los hijos de una empresa familiar, o la asociación con otros familiares (tíos, sobrinos, primos).

- La formación profesional incide en la trayectoria que lleva a la innovación, pero también hay casos en que las mujeres ven vías alternas a su profesión para poder desarrollar la empresa.

- Las mujeres se enfrentan a retos como la funcionalidad del negocio, el sostenimiento de este, la financiación y el manejo de su vida laboral y familiar, entre otros. 
Después de esta descripción del libro, es posible identificar algunos elementos esenciales en cuanto a sus aportes sobresalientes. En primera instancia, este proyecto constituye una contribución muy importante a los estudios de género, porque destaca el papel activo que tiene la mujer en Colombia, como gestora del progreso y del cambio, para demostrar que su responsabilidad en la sociedad va más allá de las funciones tradicionales a las que estuvo ligada por siglos. En segundo lugar, el documento es una herramienta indispensable en la educación empresarial para la innovación, ya que por medio de las experiencias narradas muestra los procesos que permiten la consolidación de una empresa y cómo se debe llevar a cabo el desarrollo de la innovación. Finalmente, a pesar de que el libro tiene bastantes fallas en su edición, varios descuidos relacionados con el uso del idioma y problemas de diseño, no deja de ser un estudio valioso para la formación de emprendedores en Colombia, y sirve como un eslabón para la cadena de estudios sobre el papel de la mujer como promotora y gestora de la innovación en el país. 